
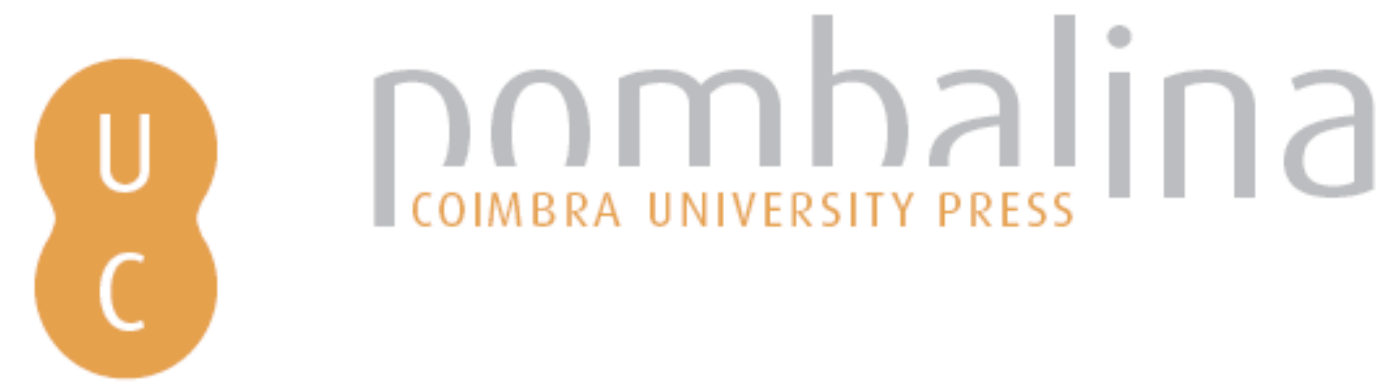

\title{
Espaço mineiro devoluto em contexto de ordenamento do território: modelo conceptual para as minas do Rebentão: Couto de Lagares: Vila Nova de Paiva
}

Autor(es): $\quad$ Alves, R. M. C.; Gomes, C. A. Leal; Valente, T. M.

Publicado por: Imprensa da Universidade de Coimbra

URL

persistente: URI:http://hdl.handle.net/10316.2/31446

DOI: $\quad$ DOl:http://dx.doi.org/10.14195/978-989-26-0531-9_19

Accessed : $\quad$ 26-Apr-2023 14:29:57

A navegação consulta e descarregamento dos títulos inseridos nas Bibliotecas Digitais UC Digitalis, UC Pombalina e UC Impactum, pressupõem a aceitação plena e sem reservas dos Termos e Condições de Uso destas Bibliotecas Digitais, disponíveis em https://digitalis.uc.pt/pt-pt/termos.

Conforme exposto nos referidos Termos e Condições de Uso, o descarregamento de títulos de acesso restrito requer uma licença válida de autorização devendo o utilizador aceder ao(s) documento(s) a partir de um endereço de IP da instituição detentora da supramencionada licença.

Ao utilizador é apenas permitido o descarregamento para uso pessoal, pelo que o emprego do(s) título(s) descarregado(s) para outro fim, designadamente comercial, carece de autorização do respetivo autor ou editor da obra.

Na medida em que todas as obras da UC Digitalis se encontram protegidas pelo Código do Direito de Autor e Direitos Conexos e demais legislação aplicável, toda a cópia, parcial ou total, deste documento, nos casos em que é legalmente admitida, deverá conter ou fazer-se acompanhar por este aviso.

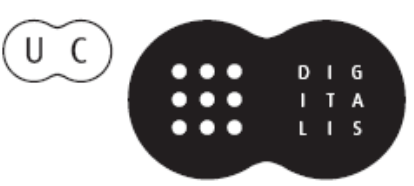





\title{
ESPAÇO MINEIRO DEVOLUTO EM CONTEXTO DE ORDENAMENTO DO TERRITÓRIO - MODELO CONCEPTUAL PARA AS MINAS DO REBENTÃO - COUTO DE LAGARES - VILA NOVA DE PAIVA
}

\author{
DERELICT MINES IN THE LAND MANAGEMENT - CONCEPTUAL \\ MODEL FOR THE LAGARES MINES -VILA NOVA DE PAIVA
}

R. M. C. Alves ${ }^{1}$, C. A. Leal Gomes ${ }^{2} \&$ T. M. Valente ${ }^{3}$

\begin{abstract}
Resumo - Em Portugal, na última década, as ações dirigidas à reabilitação de espaços mineiros abandonados tiveram principalmente incidência ambiental, ou dedicaram-se à anulação do risco geotécnico associado às escavações mineiras. Apresenta-se aqui um modelo conceptual sobre valorização de um local de interesse geológico e mineiro, onde se encara de forma mais abrangente o espaço mineiro devoluto (EMD) como uma unidade territorial com atributos geológicos e industriais relevantes a incluir no ordenamento territorial. A promoção deste EMD representa um extremo de especificidade e diversidade e baseia-se numa caracterização abrangente, geológica, mineralógica, fisiográfica, arqueológica, sócio-económica e ambiental, o que potencia variadas formas de usufruto equacionadas, atualmente, para o Couto Mineiro de Lagares.
\end{abstract}

Palavras-chave - espaço mineiro devoluto, ordenamento do território, modelo de caracterização e valorização, Couto de Lagares

Abstract - In Portugal, in the last decade, programs and actions dedicated to the rehabilitation of abandoned mining areas included environmental purposes and obliteration on hazard related to mine diggings. The conceptual model for the Lagares Mines follows a protocol of procedures which considers the mining site (MS) as a territorial unit with geological and industrial attributes, which must be considered in land-use

\footnotetext{
${ }^{1}$ Centro de Investigação Geológica, Ordenamento e Valorização de Recursos- Escola de CiênciasDepartamento de Ciências da Terra - Universidade do Minho; raquelmcepedaalvesa@gmail.com

${ }^{2}$ Escola de Ciências- Departamento de Ciências da Terra - Universidade do Minho; caal.gomes@gmail.com

${ }^{3}$ CIG-R - Escola de Ciências - Departamento de Ciências da Terra - Universidade do Minho; teresav@ dct.uminho.pt
} 
planning. This specific MS represents an extreme of identity and maximal diversity in what concerns the Northern Portugal mining industry. Its holist characterization included geological, mineralogical, physiographic, archaeological, socio-economic and environmental studies, which suggest and enhance some peculiar components of the land and local management.

Keywords - Derelict mine land, land use, characterization and valuation model, Lagares Mines

\title{
1 - Introduçáo
}

A nível internacional, a transição da atividade mineira ativa, para formas de valorização da arqueologia industrial mineira (após termo de lavra) e dos espaços naturais com ela relacionados, tem sido abordada no seguinte conjunto de conferências, organismos, programas, projetos e tarefas, por ordem decrescente de incidência específica:

\author{
1. Global Mining Initiative (1999); \\ 2. International Council on Mining and Metals (2001); \\ 3. Mining, Minerals and Sustainable Development, projeto do International Institute \\ for Environment and Development (2000-2002); \\ 4. Conferência de Estocolmo (1972); \\ 5. Comissão de Brundtland (1987); \\ 6. Cimeira da Terra (1992); \\ 7. World Summit on Sustainable Development (2002).
}

Os problemas de gestão ambiental e ordenamento que se colocam aos espaços mineiros abandonados ou devolutos têm alcançado maior visibilidade, no âmbito do planeamento regional e gestão sustentável do território, através de iniciativas como as do grupo de trabalho internacional, Post-Mining Aliance, cujo paradigma de atuação, em defesa do equilíbrio das comunidades e espaços mineiros após o termo da lavra, é representado pelo projeto de regeneração das minas da Cornualha com o Eden Project (IIED, 2000; VAN ZYL, 2002).

A Comunidade Europeia lançou diretivas e criou linhas de financiamento específicas para a reabilitação do espaço mineiro abandonado. Portugal tem usufruído destes apoios na atuaçáo da Empresa de Desenvolvimento Mineiro (EDM), empresa pública que exerce a atividade de recuperação ambiental das áreas mineiras degradadas, estabelecida pelo Decreto-Lei no 198A/2001. Em fase preliminar, a EDM inventariou 175 áreas mineiras (61 de minerais radioativos, 114 de sulfuretos polimetálicos). Trinta e cinco locais foram objeto de intervenção no que respeita à segurança, ambiente (água, solos e ar), património, aspetos humanos e paisagem (RODRIGUES, 2011). As Minas atendidas em primeiro lugar foram as que evidenciavam maior depreciaçáo da qualidade ambiental. O presente trabalho descreve um projeto de reabilitação mineira que procura a integração das múltiplas valências e utilidades do espaço mineiro, com vista à fundamentação de um programa de intervenção local que inclua espaços e objetos industriais e naturais que persistem. 
Ao nível do planeamento regional, um espaço mineiro devoluto (EMD) pode ser definido como uma porção elementar de território em cujo substrato ou superfície, com maior ou menor exuberância natural e industrial, ocorreu o aproveitamento de recursos minerais, persistindo vestígios documentais, sociais e sociológicos, topográficos, arquitetónicos, geoestruturais e paragenéticos relacionáveis com essa atividade. Em contexto de ordenamento, considera-se que o EMD é uma unidade territorial diferenciada, com valor potencial e patrimonial, cuja abordagem requer procedimentos específicos (ALVES et al., 2010).

No que se refere ao património geomineiro de Portugal, do ciclo extrativo sobre $\mathrm{Sn}-\mathrm{W}$, um dos fulcros com maior diversidade de vestígios naturais e industriais diz respeito ao Couto Mineiro de Lagares, em Vila Nova de Paiva. Aí existem vários polos de mineração dedicada ao Sn e W na primeira metade do século XX (Tabela1). Concretamente, as minas do Rebentão, sede do Couto Mineiro de Lagares, foram reabilitadas nas últimas décadas do século XX para a produção de rochas e minerais industriais cerâmicos (áreas de concessão a sombreado na Tabela1).

Após o ciclo extrativo dedicado aos cerâmicos, a empresa concessionária estabeleceu um protocolo de cooperação com o Município, equacionando a possibilidade de integrar o local no programa nacional de reabilitação de sítios mineiros abandonados.

A caracterização da componente geológica sustenta uma estratégia de reabilitação e valorização do património geológico e mineiro procurando garantir a conservação da Natureza e a oferta turística em espaço rural.

Estabeleceu-se, então, um protocolo de reabilitação em que, a par de uma primeira intervenção ao nível da caracterização geotécnica e estabilização dos antigos trabalhos, se procedeu à delimitação de uma área a promover em termos de estatuto de conservação e classificação por parte do Instituto de Conservação da Natureza e Biodiversidade.

Nesse mesmo processo iniciou-se o estudo do aproveitamento arquitetónico das infraestruturas e escavaçóes mineiras. A abordagem metodológica à reabilitação e promoçáo teria que ser multidisciplinar, aceitando-se que o ponto de vista determinante e ponto de partida seriam geológicos. Foi assim criado um modelo de diagnóstico/ caracterização e uma estratégia de valorização, em ambos os casos com incidência geológica. Este modelo sustenta a retoma do EMD, proporcionando um fundo de informação sobre potencialidades e óbices.

\section{2 - Fulcros de interesse geomineiro}

O EMD (Fig. 1) situa-se no termo SE da zona de cisalhamento do Sulco Carbonífero Dúrico-Beirão (IGLÉSIAS \& RIBEIRO, 1981). Do ponto de vista tectónico, a estruturação Varisca no sector é polifásica, sendo possível distinguir dois episódios de deformação dúctil e a atuação da deformação frágil tardia (RODRIGUES, 1997). A grande diversidade de elementos geoestruturais peculiares e bem expressos, concentrados num estreito corredor entre stocks de granitóides, determina um interesse geológico relevante para a totalidade da área do couto mineiro e domínios adjacentes. Adicionalmente, potencia a sua inclusão nas unidades territoriais sujeitas a ordenamento e gestão do património geológico e mineiro na aceção de Áreas de Interesse Geológico (AIG) e Locais de Interesse Geológico - LIG - (LIMA, 1996). 

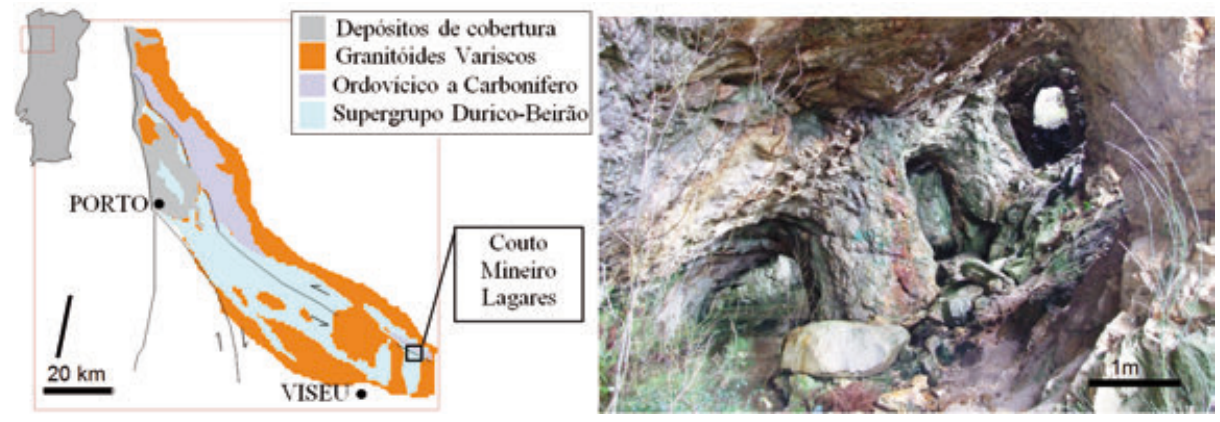

Fig. 1 - Localização do EMD na megaestrutura do Sulco Durico-Beirão. A fotografia mostra uma perspetiva do desmonte em câmaras e pilares das Minas do Rebentão - atributo ex-libris.

\section{1 - Litologia e Estrutura}

A diversidade litológica e estrutural, que é própria da megaestrutura Sulco, tem expressão numa componente fisiográfica com potencialidades paisagísticas de grande valor, onde se destacam as geoformas de erosão diferencial entre metapelitos, quartzitos, granitóides, dioritos e aplito-pegmatitos. A diversidade geológica, em sentido estrito, abrange esta diversidade litológica e ainda, intercalaçóes protolíticas tufáceas vulcanogénicas, metaruditos poligénicos (metaconglomerados), litologias metassomáticas previamente sedimentares a exalativas, ongonitos, topazitos e pórfiros (DIAS \& LEAL GOMES, 2009). Abrange também evidências de inter-relações intrusivas insólitas, com especial relevo para as massas restíticas, remanescentes da mistura de magmas (estruturas e corredores de mingling em enxames de encraves, xenocristais e xenólitos).

\section{2 - Mineralogia}

A diversidade mineralógica que se observa nos aplito-pegmatitos do Rebentão abrange um cortejo vasto de espécies, algumas das quais, no contexto português, só são conhecidas neste sítio (e.g. DIAS \& LEAL GOMES, 2009). Os minerais mais invulgares dispersam-se pela classe dos óxidos, tungstatos, sulfuretos, sulfossais, metais nativos, silicatos, fosfatos, carbonatos e haletos.

O jazigo, no seu modelo genético principal, é pegmatítico a hidrotermal e essencialmente estano-tungstífero. $\mathrm{O}$ cortejo de mineralizaçóes metálicas economicamente relevantes alarga-se aos minerais de $\mathrm{Li}$ e $\mathrm{Be}$, de $\mathrm{Nb}$ e $\mathrm{Ta}$ e de $\mathrm{Au}$ (Fig.2). As variedades mineralógicas e as dimensóes de cristais também evidenciam grande diversidade, com realce especial para a existência de gigacristais de petalite e topázio, alguns dos quais apresentam qualidade gemológica peculiar - petalite "olho de gato" (PUGA et al., 2003). 

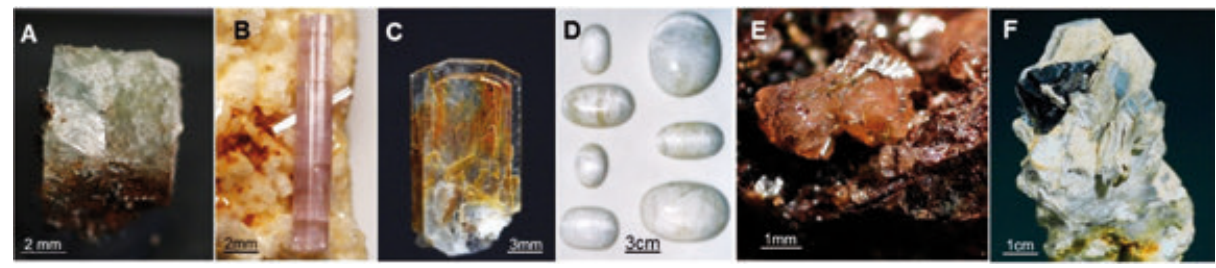

Fig. 2 - Variedades mineralógicas do EMD. A-fosfofilite, B-apatite, C-bertrandite, D-cabochons de petalite, E-hureaulite, F-cassiterite na matriz feldspática.

\section{3 - Mina}

As escavaçôes mineiras em câmaras e pilares (fotografia da Fig. 1 e Fig. 3C) sugerem possibilidades de reabilitação do EMD na perspetiva arquitetónica dedicada ao usufruto cultural e de lazer. Existe, aqui, uma traçagem muito peculiar em que o acesso das câmaras abre à superfície numa corta longitudinal a céu aberto, incidente a muro de filão (Fig. 3B). O desmonte proporciona um espaço vão subterrâneo acessível, volumoso e compartimentado, que pode ter apetências variadas a equacionar no termo do estudo, mas apresenta desde já valor arquitetónico reconhecido.

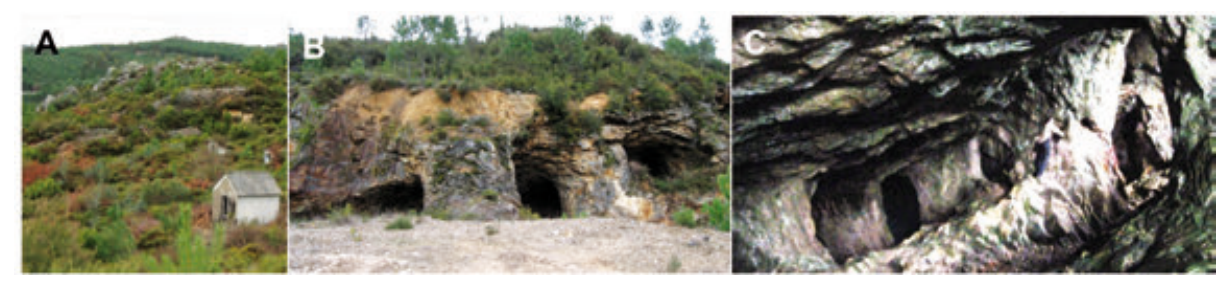

Fig. 3 - Infraestruturas do EMD. A- área dos “paióis”, próximos de acumulados de rejeitos grosseiros; B- entrada do subterrâneo; C- câmaras subterrâneas com inclinação concordante com

$$
\text { o depósito. }
$$

Também algumas infraestruturas de apoio à lavra, em maior ou menor estado de conservaçáo, têm uma identidade própria e refletem a singularidade e o cunho local do aproveitamento mineiro (Fig. 3A).

O correspondente acervo documental das concessões mineiras em causa, enumeradas na Tabela 1, está no Arquivo Histórico Geológico-Mineiro do Laboratório Nacional de Engenharia e Geologia (LNEG) e na Direção Regional de Economia do Centro (DRE-Centro), em Coimbra.

A análise espacial com base na cartografia antiga, permite definir zonas de interesse mineiro, na componente do património cultural, mas também índices com interesse extrativo remanescente. 
Tabela 1 - Concessóes do Couto Mineiro de Lagares (a sombreado) e minas vizinhas

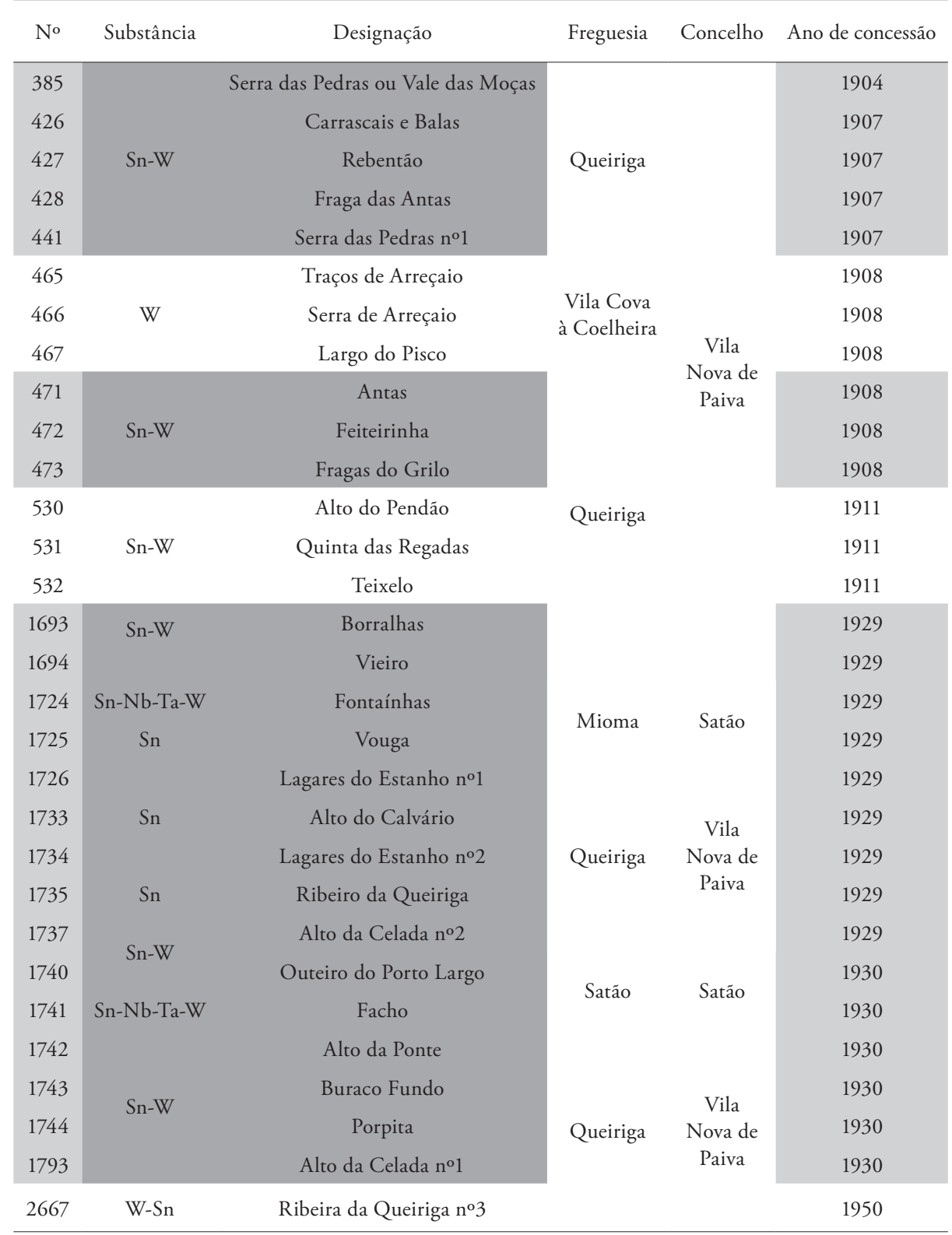

\section{3 - Modelo de diagnóstico e perspetivas de reabilitaçáo}

A elaboração de um estudo de diagnóstico do estado de conservação e das perspetivas de reabilitação incluem etapas e procedimentos calendarizadas e proporcionam a base de dados geológicos que permite definir as formas de usufruto. 
A figura 4 apresenta o modelo de ação que deve funcionar, após o início da salvaguarda, numa articulação entre atualização - qualificação - aproveitamento - reabilitação. Atendendo-se ao facto do interesse puramente económico poder persistir, devem ser estudadas formas de não o inviabilizar completamente.

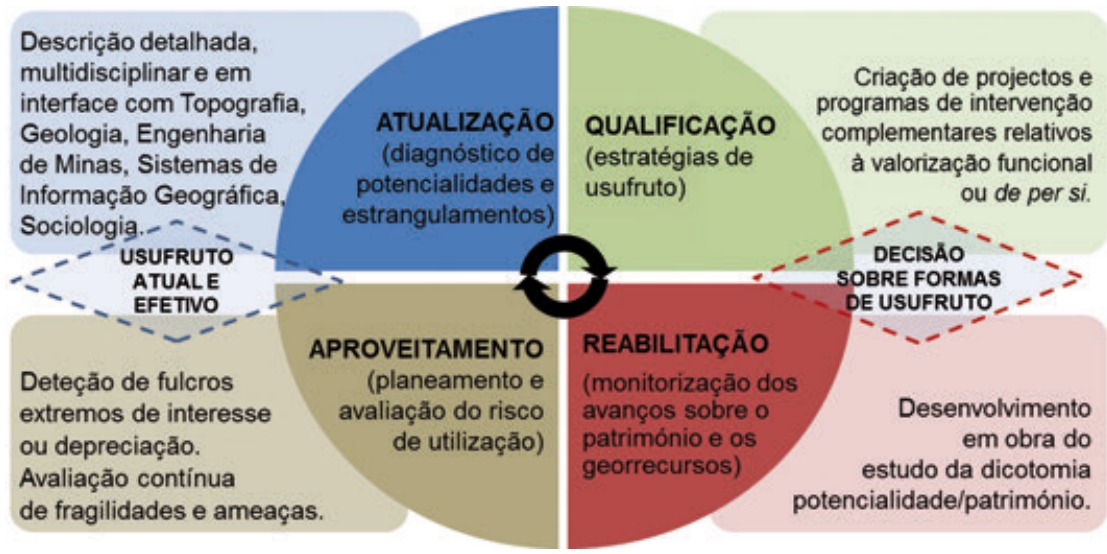

Fig. 4 - Esquema de articulaçóes dos instrumentos de planeamento como suportes de decisão em ordenamento e controlo do usufruto.

\section{4 - Previsão de resultados}

As opções de usufruto que podem ser deduzidas para a diversidade geológica e peculiaridade dos LIG's, discriminados no EM, previsivelmente obedecem à seguinte tipologia: inclusão em espaços de utilização comum; constituição de sectores temáticos; estabelecimento de reservas integrais.

Para cada uma destas opçóes distinguem-se estatutos de preservação e valorização diferenciados. Os documentos de síntese e de divulgação do programa poderão ser convertidos nos seguintes instrumentos de salvaguarda, divulgação e usufruto:

1. Plano estratégico de valorização e aproveitamento do EM;

2. Guia de campo dos LIG's;

3. Um manual descritivo dos objectos de interesse patrimonial;

4. Um manual de procedimenmtos para a salvaguarda de sítios (diretivas de conservação aplicadas à gestáo do território - apoio à intervenção das autoridades locais e agentes económicos).

É possível estabelecer, desde já, perimetros de interesse diferenciados (Fig. 5) que podem vir a ter protocolos de atuação distintos.

\section{5 - Consideraçóes finais}

Numa fase inicial, o programa permitiu extrapolar o valor patrimonial das minas do Rebentão à totalidade do Couto Mineiro de Lagares e minas das proximidades 
(Fig. 6). Assim, considerando os pequenos índices extrativos dispersos (Tabela 1), torna-se mais ampla a diversidade geológica, mineralógica e estrutural (DIAS \& LEAL GOMES, 2009), incluindo jazigos minerais primários mais diferenciados e depósitos aluvionares (rio Rebentão). Da mesma forma, o lapso temporal a que dizem respeito as exploraçóes primitivas sugere que a atividade mineira se estenda, possivelmente, até eventos pré-Romanos.

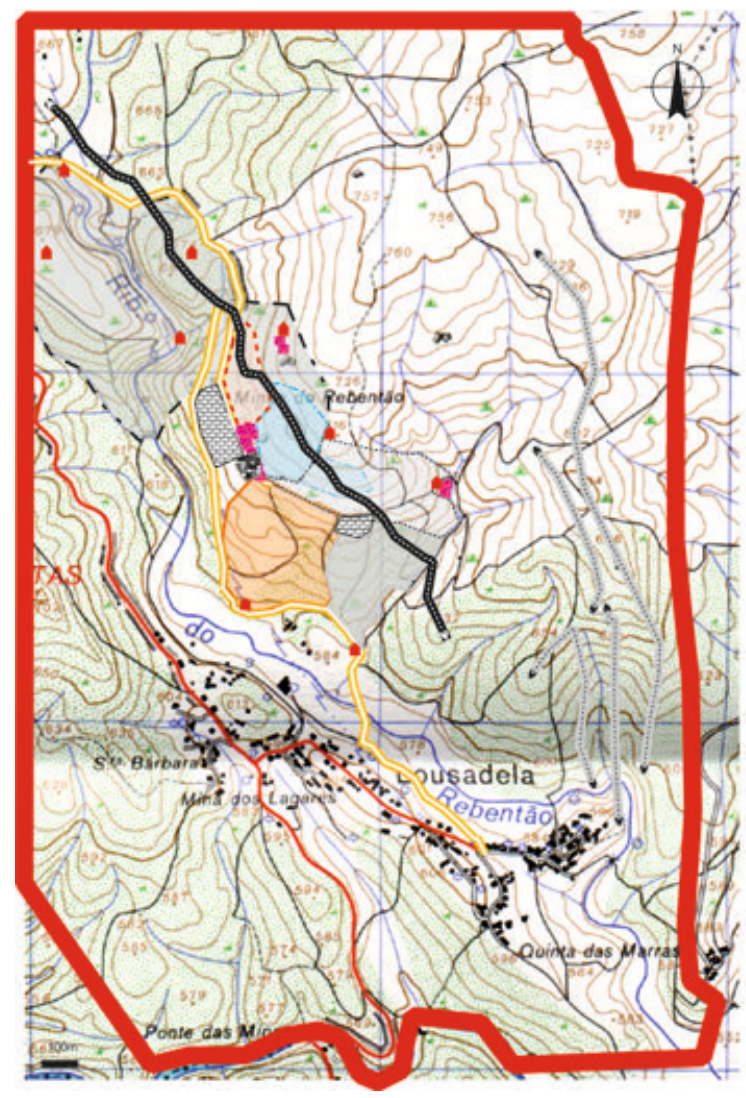

\section{EIXOS DE VALORIZAÇÃo GEOLÓGICA}

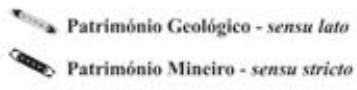

PERIMETROS COM INTERESSE GEOMINEIRO

Área de Interesse Geológico de Rebentìo

..... Fulcro minciro antigo - Ciclo do Estanho

Céu aberto recente - Ciclo Cerámico

Reabilitaçào de trabalhos minciros subterraineos (percursos com interesse museológico e lúdico)

-j Zona de interesse eco-geo-mineiro

(ambientes extremos - organismos extremófilos:

Instalą̧ăo estruturas de aproveitamento

Reabilitação de escombreiras e

regularizaçào de trabalhos antigos

TOLERÂNCIA Ả EDIFICAÇ̄̃o

m Locais para edificaçōes não penalizantes

- Guaritas de vigilância e orientaçà de visitantes

4. Recepçào e centro de interpretaçầ

Edificaçồes de acolhimento - museologia, hotelaria; restauraçåo, oficinas culturais, etc.

Fig. 5 - Área de intervenção na envolvente ao EMD. Demarcação de eixos de valorização, perímetros de interesse geomineiro e vulnerabilidade de objetos e locais.

Os estudos preparatórios do programa permitiram reconhecer que o traçado viário regional, a dinâmica dos assentamentos populacionais e os próprios mitos e tradiçóes rurais são afetados pela vivência mineira passada, através de uma herança social que, de forma mais ou menos mascarada, ainda persiste como atributo da massa crítica local, representada nos núcleos de Lousadela e Queiriga.

O programa tem, como fulcro essencial, a valorização do EMD em torno de uma reabilitação museológica das frentes acessíveis imediatamente a Sul do desmonte em câmaras e pilares no filão do Rebentão. A elaboração de um projeto arquitetónico adequado está parcialmente concluída, no que atende à primeira salvaguarda. Futuramente, 
este permitirá ilustrar e promover a diversidade de texturas, de associaçóes mineralógicas e litológicas que fundamentam o valor do EMD.

A atribuição da valência "uso comum", que diz respeito à construção de infraestruras de acolhimento e acesso, deve partir de um conhecimento rigoroso do espólio existente e das evidências naturais antes de ser gizado qualquer plano de intervenção.

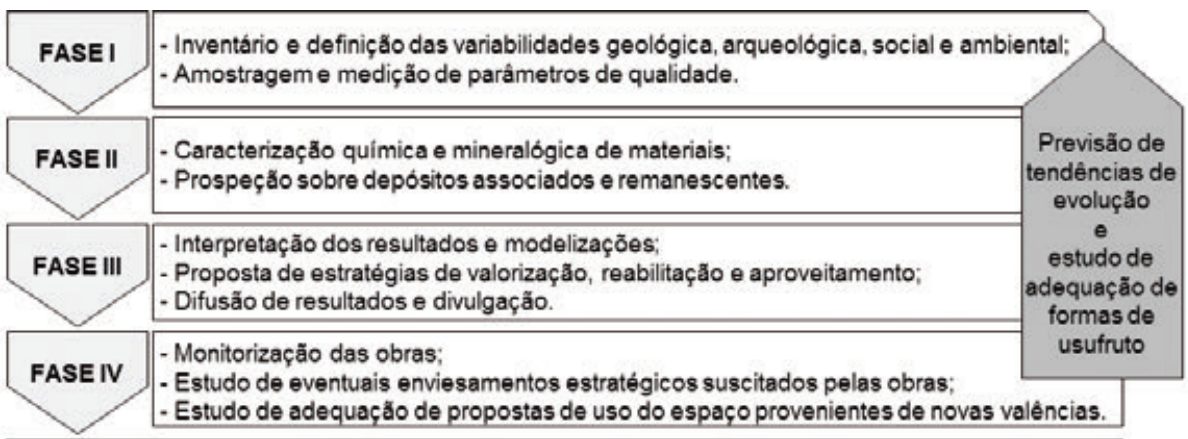

FUNDO DE INFORMAÇÃO SOBRE POTENCIALIDADES E ÓBICES NA RETOMA DO EMD

Fig. 6 - Modelo conceptual para a implementaçáo de um programa de intervenção local em contexto de reabilitação de um EMD (adap. ALVES et al., 2010)

Agradecimentos - Às entidades envolvidas no Programa de Intervenção Local - Município de Vila Nova de Paiva e Empresa FELMICA Materiais Industriais S.A. - agradecemos as informações disponibilizadas para divulgação, assim como ao Prof. Dr. Carlos Marques, responsável pelo projeto de arquitetura e coordenação formal do Programa.

O CIG-R é suportado pelo programa Plurianual da Fundação para a Ciência e Tecnologia (FCT) e pelo orçamento nacional da República Portuguesa. Este trabalho recebeu apoio da FCT através de uma bolsa de doutoramento (SFRH/ $\mathrm{BD} / 42485 / 2007)$.

\section{Referências Bibliográficas}

ALVES, R., VALENTE, T. \& LEAL GOMES, C. (2010) - Um modelo de programa para a caracterização e valorizaçáo de espaços mineiros devolutos - O caso do Couto Mineiro de Lagares do Estanho, Vila Nova de Paiva. e-Terra, Geosciences on-line Journal, Geotic, vol. 18 (19). http://metododirecto.pt/CNG2010/ index.php/vol/article/viewFile/422/373. (consultado em 2011.12.21).

DIAS, P. \& LEAL GOMES, C. (2009) - Topaz bearing tourmalinites and topazite veins from Queiriga Old Mines - Viseu - Central Portugal. Estudos Geológicos. (Special Issue of contributions to the 4th International Symposium on Granitic Pegmatites). 19 (2), pp.111-116.

IGLÉSIAS, M. \& RIBEIRO, A. (1981) - Zones de cisaillement ductile dans l' arc ibéro-armoricain. Comun. Serv. Geol. Porto. 67(1), p. 85-87.

IIED - INTERNATIONAL INSTITUTE OF ENVIRONMENT AND DEVELOPMENT (2000) - Mining, Minerals and Sustainable Development: Work Plan (Draft). London, http://www.iied.org/mmsd. (consultado em 2012.02.21). 
LIMA, F. (1996) - Itinerários Geológicos do Alto-Minho - Estudo de locais de interesse geológico. Tese de mestrado, Univ. Minho, Braga, 215 p.

PUGA, M., LEAL GOMES, C. \& VIDE, R. (2003) - Modo de ocorrência e ensaios de aplicação industrial da petalite do jazigo pegmatítico da Queiriga - Sátão (Viseu). Resumos, IV Congresso Ibérico de Geoquímica, Coimbra, p 196- 198.

RODRIGUES, J. (1997) - Estudo tectonossedimentar do extremo SE a zona de cisalhamento do Sulco Carbonífero Dúrico-Beirão (região de Queiriga - Satão, NE de Viseu). Tese de Mestrado, Univ. Lisboa, $109 \mathrm{p}$.

RODRIGUES, R. (Coord.) (2011) - A herança das minas abandonadas - O enquadramento e atuação em Portugal. EDM - DGEG. 180p. http://www.edm.pt/html/livro.html\#/14/. (consultado em 2012.02.20).

VAN ZYL, D., SASSOON, M., FLEURY, A. \& KYEYUNE, S. (2002) - Mining for the Future. Appendix C: Abandoned Mines Working Paper. MMSD. 28. http://pubs.iied.org/pdfs/G00560.pdf (consultado em 2012.02.20). 